\title{
Cleaning up the Soul to Return to Self: Analysis of the Reasons of Maislova's Resurrection
}

\author{
Niu Yan* \\ Xi'an International Studies University \\ 1 South Wenyuan Road, Xi'an, 710128, China
}

Received 25.11.2016, received in revised form 01.12.2016, accepted 12.01.2017

\begin{abstract}
"Resurrection" is Tolstoy's last masterpiece, known as "the peak of the 19th century Russian critical realism novel." The work exposed and criticized the darkness and anti-people nature of the 19th century tsarist Russia's prisons, courts and other whole state machines, at the same time preached the doctrine of "Tolstoyism", which emphasizes "non-resistance to evil by force " and "moral selfperfection". This is the results of the author's ideological exploration and artistic pursuit of up to two decades. The work tells the story of the noble intellectual Nekhlyudov finally realized the spiritual resurrection by the moral self-improvement, and the fallen Maislova in this process also came out of the fall, cleaning up the soul, returned to herself. This paper intends to explore the reasons of Maislova is resurrection from three aspects: class origin, moral probation and consciousness awakening.
\end{abstract}

Keywords: spiritual resurrection; class origin; moral probation; consciousness awakening.

DOI: 10.17516/1997-1370-0008.

Research area: philology.

\section{荡涤灵魂 回归自我}

\section{玛斯洛娃精神复活原因初探}

\section{牛妍 \\ 俄语学院 \\ 西安外国语大学 \\ 中国，西安}

文苑南路，1号，邮编: 710128

摘要: 《复活》是托尔斯泰最后一部长篇巨著, 被誉为 “19世纪俄国批判现实主义小说的巅峰”。作品 在深刻揭露和批判19世纪沙皇俄国的监狱、法庭等整个国家机器的黑暗和反人民的本质的同时, 宣 扬了 “勿以暴力抗恶” 和 “道德自我完善” 为主的 “托尔斯泰主义” 的说教。这是作家长达二十年之久 思想探索和艺术追求的结果。作品讲述了贵族知识分子聂赫留朵夫为了替曾被自己引诱后抛弃的玛

(c) Siberian Federal University. All rights reserved

* Corresponding author E-mail address: 635572082@qq.com 
斯洛娃伸冤而上下奔走, 通过道德自我完善最终实现精神复活, 而沦落风尘的玛斯洛娃在此过程中 也走出堕落, 荡涤灵魂, 回归了自我, 精神得到复活的故事。本文拟从阶级出身、道德感化、意识觉醒 三个方面探究玛斯洛娃精神复活的原因。

关键词: 精神复活; 阶级出身; 道德感化; 意识觉醒

《复活》是托尔斯泰晚年的代表作，是其世 界观转变后的主要作品, 也是托尔斯泰全部文学 创作生涯的总结。在这部作品中, 作家站在了宗 法制农民的立场上, 尖锐地揭露和抨击了19世纪 俄国的专制制度, 表达了对俄国沙皇、教会黑暗 统治的不满, 以及对生活在黑暗统治之下的广大 劳动人民的的深切同情。在小说中, 作家塑造了 生活在社会最底层、受尽屈辱和迫害的玛斯洛娃 的劳动女性形象, 塑造了聂赫留朵夫这一忓悔贵 族的典型形象, 以及玛利亚・帕夫洛夫娜、西蒙 松等政治犯形象。此外, 作者还描绘了一系列代 表俄国沙皇和教会黑暗统治的人物等等, 这是作 者对十九世纪的政治制度和人民生活状态的一 种再现。作者将每一个人物作为揭露社会黑暗面 的切入点, 全面系统地从各个角度对当时的俄国 社会进行揭露和抨击。作为生活在社会最底层的 玛斯洛娃, 走上㗏落之途的直接原因是地主阶 级造成的。从肉体和精神邽落到最终的精神复 活, 玛斯洛娃经历了漫长的荡涤灵魂, 回归自我 的过程。

\section{一、阶级出身一一玛斯洛娃精神复活的基础}

玛斯洛娃是一个被侮辱的被损害的底层妇 女的形象。她 “半是养女, 半是婢女” 的身份决定 了她是来自于社会最底层的劳动人民。少女时代 的玛斯洛娃纯洁善良, 对生活抱有美丽的幻想。 她具有底层人民善良勤劳的良好品质。自被聂赫 留朵夫玩弄和抛弃之后, 她不再相信世界上有什 么真实的东西。“从那天起, 在她身上发生一种 精神上的变化, 由于这种变化她才成为现在这 样的人。从那个可怕的夜晚起, 她再也不相信善 了。” 由此可以看出, 玛斯洛娃的堕落不是由她 出身底层阶级本质决定的, 而是由她的对立阶 级一一贵族地主阶级造成的。这是玛斯洛娃的 随落不同于聂赫留朵夫的堕落的主要原因。由此 也就决定了玛斯洛娃和聂赫留朵夫复活道路的 不同。聂赫留朵夫的复活需要从地主阶级转到
人民的立场上来, 是阶级立场的转变。玛斯洛娃 的精神复活的主要途径是从肮脏腐朽的生活回 到人民纯洁的生活中去, 是阶级的回归。“她毫 不费力, 很容易地理解了指导这些人 (革命者) 行动的动机。她自己既然出身于人民, 对他们就 十分同情。” 玛斯洛娃的底层阶级身份就决定了 她的回归, 她有纯洁善良的天性和对普通人民的 爱, 更易回归到纯洁、善良、勤劳的人民中, 这是 实现精神复活的阶级基础。

\section{二、道德感化一一玛斯洛娃精神复活的源泉}

如果说聂赫留朵夫的精神复活是从玛斯洛 娃不幸遭遇的触动开始的话, 那么玛斯洛娃的复 活正是在聂赫留朵夫的忓悔和赎罪、不惜牺牲自 己的地位和名誉的强烈的道德感化下进行的。

聂赫留朵夫第一次探监时, 玛斯洛娃还习 惯地向他媚笑, 向他要钱。他意识到当年的玛斯 洛娃已不复存在了。但在聂赫留朵夫第二次探监 时, 当他表示要用行动来赎罪, 要和玛斯洛娃结 婚时, 玛斯洛娃震惊了。她认为聂赫留朵夫是为 了拯救自己, 为了自己良心的安宁才和她结婚, 而不是因为爱她。她认为聂赫留朵夫再次为了自 己而牺牲她, 她对贵族阶级的仇恨一下子爆发了 出来, 她对聂赫留朵夫喊道: “我是苦役犯, 是 窑姐儿……, 您是老爷, 是公爵, 你用不着 跟我打交, 免得惹一身脏。你去找你那些公爵小 姐好了, 我的价钱是一张十卢布的红钞票。” “你 打算用我来拯救你自己, 你在尘世的生活里拿我 取乐还不算, 你还打算在死后的世界里用我来 拯救你自己! 我讨厌你, 讨厌你那副眼镜, 讨厌你 那张肮脏的肥脸! 你走开, 走开! ”。但在这第二 次探监之后, 玛斯洛娃心里在进行着痛苦的挣 扎。聂赫留朵夫对她说的那些话, 使她想起那个 曾经让她极尽痛苦走出来的世界。但是她知道, 再也不能忘掉过去一切, 浑浑哥哥地生活下去。 聂赫留朵夫不惜牺牲一切为玛斯洛娃上下奔走 伸冤, 为玛斯洛娃请律师, 并想要和玛斯洛娃永 
远在一起, 甚至和她一起流放的行为, 这些开始 动摇玛斯洛娃原本充满愤怒与仇恨的心。她认为 聂赫留朵夫可能真的已经意识到自己曾经的过 错, 真心想赎罪, 这种忓悔自省的精神刺激和感 染了玛斯洛娃。玛斯洛娃开始思考自己应该如何 面对未来的生活。当聂赫留朵夫第三次探监时, 玛斯洛娃已判若两人。她变得文静而胆怯, 他 从她的拒绝中听到了一种美好的东西, 感觉到 “ 她完全换成另一个人了”。玛斯洛娃决定不再喝 酒, 再也不卖弄风情, 她的内心在变化, 她的精 神在慢慢复活。

聂赫留朵夫的三次探监及其真诚的赎罪行 动对玛斯洛娃的内心产生了巨大的影响, 这种道 德感化的力量为她走向新生活提供了最初的动 力, 她开始慢慢摆脱过去的生活, 开始一种全新 的生活。

\section{三、意识觉醒一一玛斯洛娃精神复活的关键}

经过聂赫留朵夫的疏通, 玛斯洛娃调到政 治犯中间, 这使得她对自己的人生和社会产生了 不同的看法, 对玛斯洛娃的精神世界产生了极大 的影响。

玛利亚・帕夫洛夫娜是对玛斯洛娃影响很 大的女政治犯。这个美丽的姑娘出身于一个富裕 的将军家庭, 会说三种外语, 但从不卖弄风情, 炫耀自己, 这使玛斯洛娃感到特别惊讶。她从小 就厌恶贵族生活, 喜欢平民生活。“她素来不顾 自己, 永远专心寻找机会, 好在大大小小的事情 上为别人出力, 帮助别人……她生活的全 部乐趣, 就在于像猎人寻找野生的禽兽那样寻 找为别人服务的机会。”她替别人揽罪名而被判 苦役。她总是考虑怎样帮助别人, 被称为 “慈善 迷”。她非常具有自我牺牲精神。玛斯洛娃刚来 到他们 (政治犯) 中间的时候, 玛利亚对玛斯洛 娃感到憎恶和厌弃。但她仍对玛斯洛娃亲切和 蔼。在玛斯洛娃心中, 这种和蔼可亲出于这样一 个不平常的人, 使得玛斯洛娃极为感动, “结果 她把她整个的心都交给她, 不知不觉地接受她 的见解, 不由自主地在各方面模仿她。”玛斯洛 娃在很多方面都不由自主地向玛利亚靠近, 学习 她的乐于助人、自我牺牲的精神。玛斯洛娃也极 尽自己所能帮助他人, 关心他人, 甚至为无辜的
犯人求情, 改善他们的处境。她请求聂赫留朵夫 为梅尼少夫母子等其他人伸冤, 这一切行为都 预示着玛斯洛娃正在走向一种新的生活, 她的人 民意识正在觉醒。玛斯洛娃非常钦佩革命者玛 利亚, 正是在玛利亚的影响下, 她才得以改变。

西蒙松对玛斯洛娃影响极大, 甚至是 “影响 了她的前途的政治犯”。西蒙松是个非常理智的 人，他按照自己制定的标准来生活。他认为 “消 灭活物就是犯罪”, “反对战争和死刑, 而且不 但反对用任何方式杀人，甚至反对屠宰牲畜”。 他对一切实际的事情都有他自己的理论, 他定出 种种规则, 应当工作几个小时, 休息几个小时, 吃 什么样的伙食, 穿什么样的衣服, 怎样生火, 怎 样点灯等等, 他对自己要求严格, 但同别人相处 却是非常 “腼腆谦虚的”, 不过一旦作出什么决 定, 什么东西都不能阻拦他。在婚姻问题上, 他 有自己的见解，认为 “人类的繁殖仅仅是人的低 级职能, 高级职能却在于为当前活着的人服务” 。因此，他对玛斯洛娃的爱情是 “柏拉图式”。他 是把玛斯洛娃当做一个很好的、少有的、苦难深 重的人那样爱她的。他爱她, 只是希望能够帮助 她, 减轻她的厄运。他爱上了玛斯洛娃, 认为她 具有特殊的和高尚的道德品质, 在自己心目中玛 丝洛娃的地位提高了。正是在他这样一个人的真 爱下玛丝洛娃才成了一个不平凡的人, 重新获得 了人的尊严，才对自己更有信心了。玛丝洛娃的纯 洁美好的心灵得到了复苏, 她的人民意识再次觉 醒, 似乎又回到了那个纯洁美好的卡秋莎少女年 代, 重新对整个社会有了更清醒的认识, 且比以 前更加清楚地认识到自己, 明确自己应该怎样生 活, 怎样爱自己, 怎样爱他人。

玛斯洛娃与政治犯的接触标志着她实现了 真正的、完全的精神复活。她觉得这些人 “好得 出奇”, “她明白这些人是站在人民一边反对上 层人的。这些人本身就是上层人, 却为了人民不 惜牺牲他们自己的特权、自由和生命, 这就使得 她特别器重这些人, 钦佩这些人”。她从这些革 命者、政治犯身上看到了一种为正义和人民而牺 牲的精神。她拒绝聂赫留朵夫的根本原因, 就是 因为不希望自己拖累他，她爱他 “爱得很正”, “ 她是一个最有道德的人”, 她开始不仅为自己着 想, 更重要的是为聂赫留朵夫着想。她与革命者 
接触过程中荡涤了自己的灵魂, 回归了自我。她 最终与革命者的结合意味着她走上了愿意为他 人牺牲自己的利他主义道路, 从此, 玛斯洛娃真 正地复活了。

\section{四、结语}

玛斯洛娃的精神复活经历了从陏落、疑惑、 忓悔、赎罪、感化、荡涤的漫长的过程。从纯真 少女到沦落风尘, 最后回归自我, 她在荡涤灵魂 的道路上艰难地前行着。从不再相信善, 相信上
帝, 到再次相信上帝, 她精神的最终复活与她的 底层阶级出身、聂赫留朵夫忓悔赎罪行为的感化 是分不开的, 而与政治犯的接触使得她重新认识 了自己和整个社会, 并最终走上了精神的复活, 获得了全面的新生。列夫 - 托尔斯泰十分钟爱自 己塑造的人物, 他让他们经历痛苦的挣扎后, 通 过宽恕和博爱、道德的自我完善等不同方式最终 实现精神的复活, 获得全面的新生, 这就是以 “ 道德自我完善” 为主的 “托尔斯泰主义” 的重要 内容。

\section{参考文献}

Tolstoi, L.N. (1995.). Voskresenie [Resurrection]. Moscow, Sinergia, 544 p.

曹靖华. 俄国文学史 [Eguo wenxue shi]: 上卷[M].北京:北京大学出版社, 2007年。

都本海. 玛斯洛娃的精神复活和托尔斯泰的人道主义“救世新术” [Ma si luo wa de jingshen fuhuo he tuo er si tai de rendao zhuyi “Jiushi xin shu”]. 东北. 师大学报. 1985(1).

李默. 浅析《复活》中的主要人物形象 [Qian xi “fuhuo” zhong de zhuyao renwu xingxiang]. 青 春岁月. 2013 (10).

\section{Причины духовного воскресения Екатерины Масловой: очищение души и возвращение к себе}

\section{Ню Янь}

Сианьский университет иностранных языков Китай, 710128, Сиань, ул. Вэньюань, 1

\footnotetext{
Роман «Воскресение» является последним эпическим произведением Л.Н. Толстого, известным как «вериина русского критического реализма романов ХІХ века». Это произведение посвящено выявлению и критике иарской тюрьмы, суда и государственной машины, направленной против народа. Данное сочинение мы анализируем с позиции проповедуемых идей «толстоизма», заключающихся в необходимости «постоянного самосовершенствования».
}

Ключевые слова: духовное возрождение, класс происхождения, нравственное влияние, сознание.

Научная специальность: 10.00.00 - филологические науки. 